\title{
Sexual Harassment of Female Providers by Patients: a Qualitative Study
}

\author{
Cecilia Scholcoff, MD MPH ${ }^{1,2}$ (D), Amy Farkas, MD MSc ${ }^{1,2}$, Julie L. Machen, MD ${ }^{3}$, \\ Cynthia Kay, MD MSc ${ }^{1,2}$, Sarah Nickoloff, $M D^{1,2}$, Kathlyn E. Fletcher, $M D M A^{1,2}$, and \\ Jeffrey L. Jackson, MD MPH ${ }^{1,2}$
}

${ }^{1}$ Clement J. Zablocki VA Medical Center, Milwaukee, WI, USA; ${ }^{2}$ Medical College of Wisconsin, Milwaukee, WI, USA; ${ }^{3}$ Dell Medical School at the University of Texas, Austin, TX, USA.

\begin{abstract}
BACKGROUND: Sexual harassment of women is a pervasive problem. Prior studies found that sexual harassment of female providers by patients is common, but guidance on addressing this problem is limited.

OBJECTIVE: To understand the experiences of female providers with sexual harassment by patients with a focus on how practicing providers address these events.

DESIGN: Qualitative study using semi-structured interviews.

PARTICIPANTS: Twenty female, internal medicine providers, including resident physicians, staff physicians, and nurse practitioners at a large, urban, academic hospital in the USA.
\end{abstract}

APPROACH: Interviews were analyzed for themes.

KEY RESULTS: Two themes were explored: first, the experiences with sexual harassment and, second, the strategies to address sexual harassment. We coded four subthemes regarding participant experiences: (1) their descriptions of the types of harassment, (2) the context of the event, (3) the impact of the harassment, and (4) their preparation to address the harassment. We coded seven sub-themes on strategies used by participants: (1) indirect strategies, (2) confrontation, (3) modifying the clinical encounter, (4) modifying self, (5) alerting others, (6) debrief, and (7) report.

CONCLUSION: Our qualitative study found that sexual harassment of female providers by patients is an ongoing problem, disruptive to the patient-provider relationship, and a possible threat to the well-being of both provider and patient. Formal training on how to address this problem was lacking, but all providers had developed or adapted strategies based on personal experiences or role modeling. Educating providers on strategies is an important next step to addressing this problem.

KEY WORDS: sexual harassment; physician-patient relationship; women in medicine.

We presented an earlier version of this manuscript as a poster at the Society of General Internal Medicine national meeting in Washington, DC in May 2019

The opinions expressed in this article reflect those of the authors and should not be construed in any way to be those of the US Government or the Department of Veterans Affairs.

Received October 11, 2019

Accepted June 30, 2020

Published online July 22, 2020
J Gen Intern Med 35(10):2963-8

DOI: $10.1007 / \mathrm{s} 11606-020-06018-3$

(C) Society of General Internal Medicine (This is a U.S. government work and not under copyright protection in the U.S.; foreign copyright protection may apply) 2020

\section{INTRODUCTION}

Sexual harassment of women is pervasive and is defined as unwelcome sexual advances, requests for sexual favors, and other verbal or physical conduct of a sexual nature. ${ }^{1}$ Studies from the 1990s reported that female medical students, ${ }^{2}$ residents, ${ }^{3}$ and practicing clinicians ${ }^{4,5}$ experience sexual harassment by patients and more recent studies confirmed this as an ongoing problem..$^{6-9}$ Although all these studies describe the scope of the problem, clear guidance on how to address it is minimal.

Current literature on how to address harassment is limited to two survey-based studies, which categorize common responses used by female providers to combat harassment, and a theoretical framework for how providers could respond to patient-driven harassment. ${ }^{10-12}$ More recently, one intervention published from a surgical training program at Massachusetts General Hospital included some aspects on how to deter gender-based harassment from patients. ${ }^{9}$ However, none of these publications utilized interviews to obtain participants' experiences and responses in their own words. They highlight the need for ongoing evaluation and understanding of what providers are enduring and how to address sexual harassment from patients.

Our study purpose was to explore the experiences of female providers with sexual harassment by patients with a focus on how practicing providers address these events.

\section{METHODS}

We conducted semi-structured interviews with female residents, attendings, and nurse practitioners at a tertiary academic medical center. The purpose of these interviews was to understand provider experiences with sexual harassment from patients and the strategies they use to address these incidents. The study was approved by our IRB. Subjects received no incentive for participating. 


\section{Participants and Recruitment}

The study was conducted in the fall of 2018. We recruited a convenience sample of Department of Medicine female practitioners via monthly emails that outlined the study purpose. Thirty-five staff providers and forty-eight resident providers were emailed during the recruitment period. Email respondents were contacted by the study coordinator, who explained the project in more detail and arranged interviews by one of five trained interviewers (JLM, CS, AF, CK, SN). All participants provided written informed consent prior to participation.

\section{Interviews}

We developed an interview guide (supplement) based on a literature review and discussion among an expert panel of providers. The interviews were piloted among a group of female attending physicians for flow, length, and clarity. The interview questions were open-ended with prompts that interviewers could use as follow-up questions. All interviews were audio-recorded and transcribed verbatim. In preparation, the five interviewers discussed the need for an open approach and three interviewers had completed qualitative methods course work during fellowship training. The interviewers participated in taped practice interviews; these audiotapes were reviewed by one of the coders (JLJ) for interview fidelity and openness of the approach.

\section{Analysis}

Two authors (KEF, JLJ) coded the de-identified transcripts for themes using thematic content analysis, an iterative approach with the goal of finding patterns across the dataset. ${ }^{13,14}$ The two authors reviewed the first four transcripts together to develop an initial coding scheme through an interactive process of discussion and consensus building. Subsequently, they independently coded transcripts, meeting regularly to compare themes. This process continued until no new themes emerged. In consultation and over several sessions with the two coders (KEF, JLJ), a third author (CS) reviewed the themes and developed a framework for understanding the experience of harassment and the strategies used to address it. Coding was done with NVivo (v4, QSR International).

\section{RESULTS}

Our sample consisted of twenty female providers: six resident physicians, thirteen attending physicians, and one nurse practitioner. Two major themes were explored: the experiences with sexual harassment from patients and the strategies used to address sexual harassment. Our analysis highlights the key findings for these two themes and delves into the sub-themes for each.
Table 1 Theme 1: Experiences of Sexual Harassment

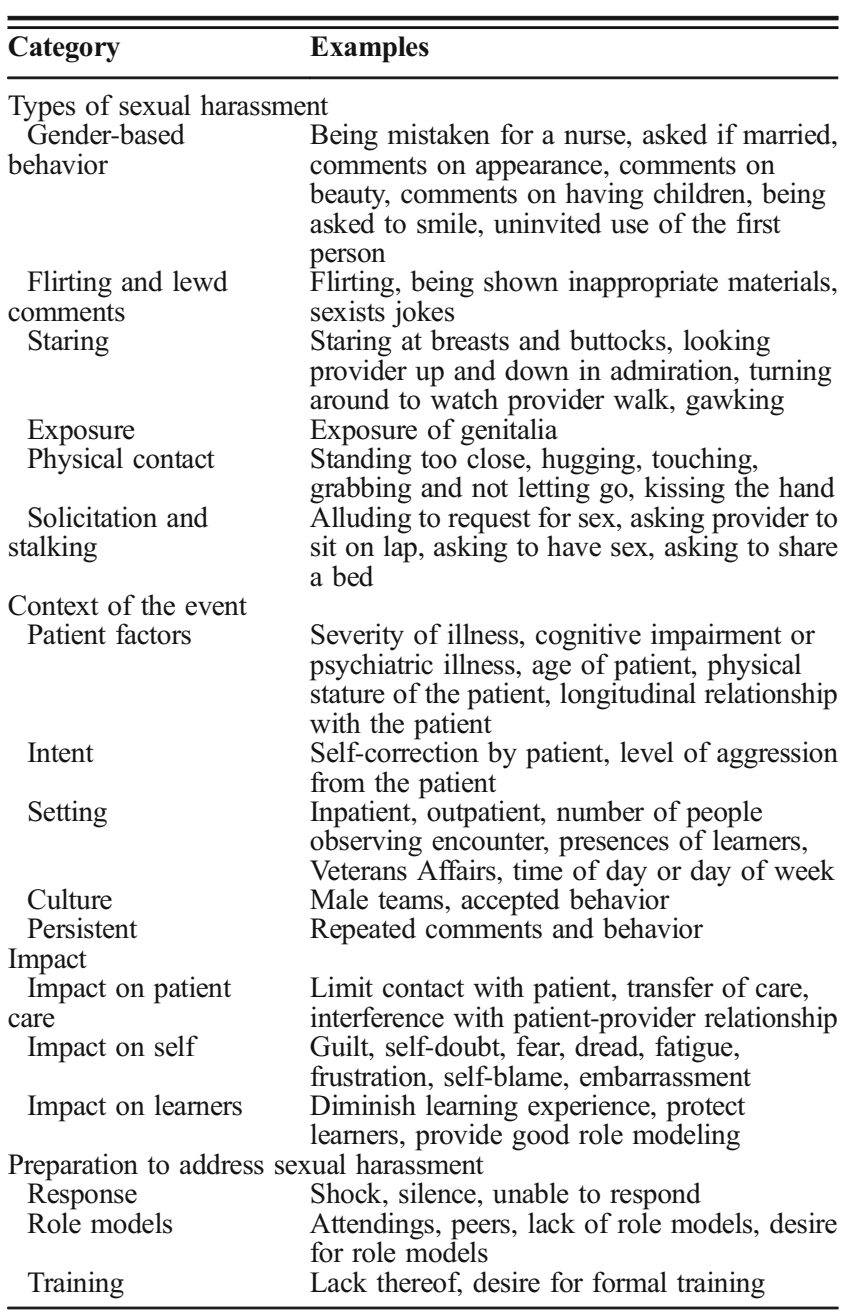

\section{THEMATIC ANALYSIS}

\section{Theme 1: Experiences with Sexual Harassment}

All participants described their experience with sexual harassment from patients and many found these experiences common. From participant discussion, we coded four sub-themes: the descriptions of the types of sexual harassment, the context of the event, the impact of the harassment, and the preparation to address harassment (Table 1).

Descriptions of the Types of Sexual Harassment. We coded six categories of harassment: (1) gender-based behavior, (2) flirting and lewd comments, (3) staring, (4) exposure, (5) physical contact, and (6) solicitation and stalking. Genderbased behavior ranged from being identified as a nurse to comments on physical appearance to defiance in following instructions during a clinical encounter. One participant found that: "If I'm with my male medical students, older men will look toward the male medical student to ask all their questions." Most of these behaviors were identified as harassment, but some (such as being misidentified as a nurse) were not 
endorsed as sexual harassment by all providers. Providers found these behaviors bothersome and disruptive.

Overt flirting, lewd comments, staring, exposure of genitals, and unwanted physical contact were also reported and universally identified as harassment. One provider highlighted: "occasionally patients want a hug and they're a little grabby with the hug, they invade your personal space inappropriately with sexual overtones." More egregious violations of the patientprovider relationship, such as overt solicitation for sex and stalking, were also experienced by some participants. One described a patient who made comments to female staff such as "why don't you come into my room and see me, I could really use your company, it would be nice if you sat on my lap."

Context of the Event. Participants felt that determining if a comment or behavior was sexual harassment and the severity of such was based on several contextual factors: patient factors, intent, setting, culture, and persistence. Patient factors, such as age and medical and psychiatric conditions, were thought to be important: "Another incident... was just an older, demented patient who just made [comments]: 'You're as cute as bow,'... he was demented, it wasn't intentional." Interviewees also discussed the intent of the patient as a key component to understanding the interaction, though intent was often difficult to delineate: "Some of my patients, I feel like they don't mean it in a sexual harassment kind of way. I think they generally are trying to be nice." The setting (e.g., clinic or hospital ward and the presence of others) and the culture and expectations surrounding acceptance of these behaviors also altered participants' interpretation of the event. One participant highlighted the importance of the setting: "Especially the ones in the hospital, when we're doing inpatient wards, that's a little bit different because I don't know them as well. So some of those comments do make me feel uncomfortable, especially with residents and medical students around." Lastly, they noted that persistence of a comment or behavior could change the interpretation from benign to harassment: "The first time, it's easy maybe to make that mistake. I think what is pretty frustrating is continually being identified as a patient's nurse."

Impact. Providers perceived that sexual harassment by patients impacted patient care, providers, and learners, affecting the way they delivered care and how they felt during and after an encounter: "I am looking at the clock to know when I need to cut this person off and send them on their way. Which, actually, makes me feel a little bit guilty, because I feel like I'm not treating all of my patients the same way. But I feel a lack of respect." In addition to describing guilt, they identified feeling fatigued, degraded, discouraged, and unsafe: "I'm a doctor, I have worked really hard to get to where I am, and you're basically just taking that away from me." Another provider remarked: "Even though I was not physically attacked, I was emotionally attacked. I felt as if I was raped and violated." They also reported self-blame: "'Did I do something differently this visit? No, I'm dressed as plainly as possible.' You're going through the things that most women do when something like this happens. What about me did that?"

Some participants reported a desire to protect learners from harassment but identified a struggle between providing protection and education: "There are patients who seem inappropriate and I have not had a medical student go in if that's an option. I have had a patient transferred out of the resident clinic for that purpose. So, I've tried to protect learners ... in one sense, you're protecting them, right? But then, in the other sense, what are they going to do when they're attendings?"

Preparation to Address Harassment. Many felt unprepared to address sexual harassment: "I was so taken aback by it that I was scrambling to figure out the appropriate professional response." Some providers noted a lack of role models, although others commented that prior attendings or peers had helped them develop tactics to address this problem. Several providers reported a lack of training on how to deal with sexual harassment from patients: "I can't say that I went through any kind of training. I think it's more [observing] behaviors and listening to advice from other people." A few mentioned online trainings for how to address harassment in the workplace but noted that these trainings were not effective or applicable to patient situations.

\section{Theme 2: Strategies to Address Sexual Harassment}

All participants discussed strategies they used to address sexual harassment from patients. We coded seven sub-themes detailing the strategies used by our participants: indirect strategies, confrontation, modifying the encounter, modifying self, alerting others, debrief, and report (Table 2).

Indirect Strategies. Indirect strategies were the most common method for addressing gender-based comments and sexual harassment. Almost all providers highlighted these strategies, which included avoiding parts of the patient interview or exam, ignoring the comment, redirecting the conversation, or using humor: "I awkwardly laughed ... Because I didn't really know what else to do." Most providers found that indirect strategies worked well, and they were able to proceed with patient care. However, several commented that these strategies were not ideal as they did not address the problem and left them feeling distressed: "As I reflect on it I'm disappointed in myself for not responding." Several interviewees noted that they used indirect strategies because they were surprised by the encounter and had no other strategies in mind.

Confrontation. Many providers discussed instances where they confronted the patient: "I'm way more likely now to 
Table 2 Theme 2: Strategies to Address Sexual Harassment

\begin{tabular}{l}
\hline \hline Strategy \\
\hline Indirect \\
Avoid: avoid physical exam, sexual history, or \\
hallways
\end{tabular}

Ignore: ignore comment, pretend it didn’t happen, move on, limit answers

Humor: laugh it off, exaggerated response for humor

Redirect: change the subject, redirect back to their health, start physical exam

Non-verbal cues: distance between patient and provider

Confrontation: alert patient that behavior is inappropriate and not acceptable

\author{
Modify encounter \\ Introduce self as doctor \\ Depersonalize: share fewer personal details, more \\ impersonal or professional \\ Leave door open \\ Chaperone: see patient as a team, with nurse or \\ preceptor \\ Limit duration of visit
}

\begin{abstract}
Modify self
Avoid certain clothing: dresses, skirts, heels
\end{abstract}

Wear identification: white coat, name badge with title

Alert others: document in chart, verbal alert

Debrief: with colleagues, with family

Report: limited reporting, not sure who to report to

\section{Representative quotation}

I typically stay in my office, which is terrible, and in clinic. Try to stay put in one place and not move throughout the hallway. Especially during certain times because I know that it's either gonna be extra attention that...I don't need.

Just looking at my computer screen and trying not to engage. I didn't correct the patient.

Trying to put some humor in there, or making it obvious that it's ridiculous, or even having an exaggerated response, it's like: "What? Like, why would you think I would be interested in you, you're so old?"

I find redirection to be the most helpful thing possible, because then again, if you redirect it to their health, realizing, "Hey, this is why we're in the room. Not to talk about me, or my appearance, or what's going on with me, but about you, this is your time for your health," is probably the best.

So, I basically addressed it by physically changing where I was standing in the room... I sort of created more space between myself and the patient

He had said to my medical student "when you're in the room I want you to be smiling, why don't you give me smile?" And I could tell that that was very uncomfortable and awkward for her, and I said, "that's not her role here as a medical student and you don't have a right to tell her to do that. We are here to do our jobs, and that's not part of our job."

Now when I walk into a room I always say, "And I am your doctor."

If I find that a patient is inappropriate and I have to draw boundaries, then my personality might shift a little bit [from] being more personable to being just more black and white. A little more distant or stand-offish.

I'm more likely to leave the door open.

I got a weird vibe so I actually went out... and brought the preceptor back in.

[If] I know that it's gonna be one of these interactions with someone who has behaved in a way that's made me uncomfortable before, I...talk to the other staff in the clinic to let them know that I probably am not gonna be able to be in this room for longer than this period of time, because of levels of discomfort. And that they should come check in on me.

I've stopped wearing dresses. I've had to censor what I'm wearing. I don't dress inappropriately at all, and frankly I don't think it should matter what I wear, but I just try to wear very conservative stuff.

I introduce myself as Dr. XXX. I literally wear a white coat still. I think that's important. Even in primary care clinic, I'm wearing my white coat so it clearly identifies myself.... it's like, "No, I'm the doctor"'

The LPN, she'd stop me to say that she felt very uncomfortable checking him in because of comments that he had made to her, which kinda heightened my radar, I guess, to this interaction.

I feel like there is something therapeutic about being able to express the way that it made you feel, and to have support from your colleagues that you're not wrong in feeling that way. To be honest I don't even know who I would report to. say, 'Hey, that's inappropriate. Do not do that.' Or, 'That's not okay in my clinic." Providers reported struggling between confronting the patient and maintaining good provider-patient relationships. Fear of embarrassing the patient and damaging the relationship was often cited as concerns when confronting patient behavior. Providers discussed two common reactions to the confrontation strategy. Patients who were not aware that their comments were inappropriate usually apologized: "Once I've addressed it with them, it wasn't really an intentional thing to put you down or to make you feel bad. I think just directly communicating with them that that's not okay is the best way to do it." Other patients became defensive and told the provider that she was being overly sensitive; however, no provider reported having a patient terminate their relationship after a confrontation event. One participant said: "It has not been a horrible situation. I've been 'fired' for many reasons but having that conversation has not been one of them."

Multiple participants commented that they were more apt to confront the patient in situations that included learners. They identified two reasons for this: a desire to set a good example and a need to mitigate the harassment of learners. One provider highlighted: "I didn't know it was appropriate to say it when I was a student, or an intern, or even a resident. Now I'm just thinking, if I don't set an example for the team, because I never saw anybody else say anything, then why would they ... it was just going to be the same thing." Another reported: "Immediately, in front of the learner and the patient, because I was like, 'Oh no. That cannot happen to my learner."'

Modify Encounter. Providers identified many ways in which they altered the encounter to deal with sexual harassment. First, they reported being less personable and more distant with these patients: "I usually use last names with patients. I don't use first names." Next, providers altered their clinical interview or exam, such as avoiding sexual history questions and avoiding part or all of the physical exam. In situations with a patient known to harass female staff, many participants would leave the door open, enter with another staff member, 
or have another staff member check in on them during the encounter: "My senior resident and I went to go see him together, just because we had read in the chart that he was already making some inappropriate comments to nursing staff." Some reported terminating the visit early or transferring the patient's care to a male provider.

Modify Self. Most participants modified themselves or how they presented themselves to mitigate sexual harassment, including wearing less or no make-up, altering their hair, and avoiding certain clothing, such as skirts, dresses, or heels: "I don't wear dresses to my men's clinic anymore ... I always wear pants." Multiple providers identified using their white coat or a name tag to further identify themselves as a provider and deemphasize their physical appearance: "I probably wore my white coat more often ... to kind of place myself in that role, even though wearing a white coat or not doesn't change the fact that I'm a doctor." Despite the visual cues of white coats and name tags, patients often struggled to identify them as providers during the visit: "I was always assumed to be a nurse."

Alert Others. Participants found that documentation in the chart or a verbal warning about inappropriate behavior was beneficial: "It's helpful when someone has a flag in their chart that this patient shouldn't be seen by a female provider by herself or he has a history of making sexual comments. Then my guard is up."

Debrief. Female providers relied on discussing these events with peers for support and assistance with coping: "I like talking to other people so I feel like if someone makes an egregious comment I'll probably tell one of my coworkers, friends." Resident providers commented that having preceptors debrief about these incidents was helpful: "We kind of did a debrief and just both sat down and said, 'You know what? That made me feel really uncomfortable. That was not part of our medical exam'... The debriefing I think was helpful."

Report. Most providers had not reported prior events of harassment; many felt the harassment did not reach a level which needed to be reported: "I've had patients inappropriately stare at me. I would like to hope that I would report a patient who physically touched me in an inappropriate way." Another described the need to report in terms of patient care: "If I ever felt that the patientdoctor relationship had been compromised to the point that I wasn't able to do my job safely or mentally, then I think it would be my duty to the patient to report." Many participants were aware of reporting mechanisms, but some felt unsure how to report sexual harassment from patients specifically.

\section{DISCUSSION}

Our qualitative study suggests that sexual harassment of female providers by patients continues to occur and that many feel unprepared to address it. Most harassment was verbal, in the form of patient comments, and the patient's intent was sometimes difficult to decipher. Moreover, many behaviors had to be judged within the context of patient factors, such as dementia. Providers struggled with a desire to preserve the patient-provider relationship. Consequently, the most common strategy our participants used to deal with harassment was to ignore it and redirect that patient back to the visit's purpose.

Our results, as well as others recently published, ${ }^{6-8,15}$ share many similarities to studies published over 25 years ago,, 11 suggesting that, although more women have entered the field of medicine, little has been done to consistently and systematically address this issue. Providers receive little training about how to address sexual harassment from patients, and workplace sexual harassment training is generally not applicable to these situations.

Sexual harassment is a predictor for provider burnout, depression, and job dissatisfaction. ${ }^{16,17}$ Our providers found all types of harassment, including gender-based comments, to be bothersome and disruptive to the patient-provider relationship as well their sense of self. Furthermore, our results and others find that patient care may be disrupted or jeopardized due to these patient-initiated behaviors. ${ }^{10,18}$ Hence, there is a need to address this problem for the health and safety of both patients and providers. Unfortunately, most institutions do not have systematic approaches to remedy sexual harassment by patients and provider training is scarce. ${ }^{12,18}$

In our study, female providers reported multiple strategies that they have developed or adapted, mostly based on personal experience and role modeling. Our study was not designed to compare these different strategies, but it is important for providers and health systems to understand which strategies are likely to result in the best patient care and provider well-being. An algorithm for how to address sexual harassment from patients was recently published by Viglianti et al.. ${ }^{12,19}$ This algorithm recommends first assessing for provider safety, then, if the provider feels safe, he/she should confront the patient to stop the behavior. If the behavior is stopped, then patient care can continue; however, if the behavior persists or the provider feels unsafe, the provider should stop patient care, report, and consider transfering care. The results of our study support this algorithm in that direct confrontation was usually effective, rectified the problem, and deterred further issues.

Our results also found that participants valued debriefing, either formally with a supervisor or informally with peers. Debriefing with trainees seems to be of particular importance as many of our participants commented that they would have appreciated it during their own training. Although defriefing is 
not yet proven to reduce physician burnout, small studies are promising and debriefing is generally used to improve providers' ability to handle stressful patient care situatios. ${ }^{20-22}$

Additionally, it is important that institutions bring attention to these common occurrences and provide training on how to effectively handle these situations. Some participants were shocked and stunned into silence by patients' comments and behaviors. Therefore, an open dialogue and formal training may improve providers' readiness to respond appropriately. Instruction should include bystander training for those who witness harassment.

Our study has limitations. First, selection bias is possible since providers who have encountered harassment may have been more likely to participate. Alternatively, female providers experiencing long-term adverse effects due to harassment may have avoided participation. Additionally, we are a single Midwestern site; our study reflects the experiences at a large tertiary urban hospital and the experiences in other settings could differ. Next, we did not ask our participants the gender of patients from whom they received harassment, but, to the knowledge of our coders, all the patients were referred to as "him." Lastly, we did not collect demographic information such as age, years of experience, sexual orientation, or gender identity which could have an impact on how harassment events were experienced.

In summary, our participants reported that sexual harassment of female providers by patients is common and disruptive to the patient-provider relationship. It is also a threat to the health and well-being of both provider and patient. Training providers on strategies is an important next step to addressing this problem.

Corresponding Author: Cecilia Scholcoff, MD MPH; Clement J. Zablocki VA Medical Center, Milwaukee, WI, USA (e-mail: cscholcoff@mcw.edu).

\section{Author Contribution None.}

Funding Information This study was funded by the Medical College of Wisconsin Faculty Development Award.

\section{Compliance with Ethical Standards:}

Conflict of Interest: The authors declare that they do not have a conflict of interest.

\section{REFERENCES}

1. Association AM. Sexual harassment in the practice of medicine 2018 . Available from: https://www.ama-assn.org/delivering-care/ethics/sexual-harassment-practice-medicine. Accessed May 23, 2019.

2. Connolly MJ. Results of the Committee on Women Physicians' survey. Minn Med. 1993;76(9):21-3.

3. Cook DJ, Liutkus JF, Risdon CL, Griffith LE, Guyatt GH, Walter SD. Residents' experiences of abuse, discrimination and sexual harassment during residency training. McMaster University Residency Training Programs. CMAJ. 1996;154(11):1657-65.

4. Blumenreich P. Sexual harassment of female physicians by male patients. J Ky Med Assoc. 1993;91(7):291-2.

5. Phillips SP, Schneider MS. Sexual harassment of female doctors by patients. N Engl J Med. 1993;329(26):1936-9. https://doi.org/10.1056/ NEJM199312233292607.

6. Vargas EA, Brassel ST, Cortina LM, Settles IH, Johnson TRB, Jagsi R. \#MedToo: A Large-Scale Examination of the Incidence and Impact of Sexual Harassment of Physicians and Other Faculty at an Academic Medical Center. J Women's Health (2002). 2019. https://doi.org/10. 1089/jwh.2019.7766.

7. Hu YY, Ellis RJ, Hewitt DB, Yang AD, Cheung EO, Moskowitz JT, et al. Discrimination, Abuse, Harassment, and Burnout in Surgical Residency Training. N Engl J Med. 2019;381(18):1741-52. https://doi. org/10.1056/NEJMsa1903759.

8. Fnais N, Soobiah C, Chen MH, Lillie E, Perrier L, Tashkhandi M, et al. Harassment and discrimination in medical training: a systematic review and meta-analysis. Acad Med. 2014;89(5):817-27. https://doi.org/10. $1097 / \mathrm{acm} .0000000000000200$.

9. McKinley SK, Wang LJ, Gartland RM, Westfal ML, Costantino CL, Schwartz D, et al. "Yes, I'm the Doctor": One Department's Approach to Assessing and Addressing Gender-Based Discrimination in the Modern Medical Training Era. Acad Med. 2019;94(11):1691-8. https://doi.org/ 10.1097/acm.0000000000002845

10. Ulusoy H, Swigart V, Erdemir F. Think globally, act locally: understanding sexual harassment from a cross-cultural perspective. Med Educ. 2011;45(6):603-12. https://doi.org/10.1111/j.1365-2923.2010.03918.x.

11. Phillips S. Sexual harassment of female physicians by patients. What is to be done? Can Fam Physician. 1996;42:73-8.

12. Viglianti EM, Oliverio AL, Meeks LM. Sexual harassment and abuse: when the patient is the perpetrator. Lancet. 2018;392(10145):368-70. https://doi.org/10.1016/s0140-6736(18)31502-2.

13. Braun V, Clarke V. Using thematic analysis in psychology. Qual Res Psychol. 2006;3(2):77-101. https://doi.org/10.1191/ 1478088706qp063oa.

14. Crabtree BF, Miller WL. Doing qualitative research. Thousand Oaks: Sage Publications, Inc; 1992. xvi, 276-xvi.

15. Jagsi R, Griffith KA, Jones R, Perumalswami CR, Ubel P, Stewart A. Sexual Harassment and Discrimination Experiences of Academic Medical Faculty. JAMA. 2016;315(19):2120-1.

16. Takeuchi M, Nomura K, Horie S, Okinaga H, Perumalswami CR, Jagsi R. Direct and Indirect Harassment Experiences and Burnout among Academic Faculty in Japan. Tohoku J Exp Med. 2018;245(1):37-44. https://doi.org/10.1620/tjem.245.37.

17. Frank E, Carrera JS, Stratton T, Bickel J, Nora LM. Experiences of belittlement and harassment and their correlates among medical students in the United States: longitudinal survey. BMJ. 2006;333(7570):682.

18. Bratuskins PA, McGarry HA, Wilkinson SJ. Sexual harassment of Australian female general practitioners by patients. Med J Aust. 2013;199(7):454..

19. Paul-Emile K, Smith AK, Lo B, Fernández A. Dealing with Racist Patients. N Engl J Med. 2016;374(8):708-11. https://doi.org/10.1056/ NEJMp1514939.

20. Gunasingam N, Burns K, Edwards J, Dinh M, Walton M. Reducing stress and burnout in junior doctors: the impact of debriefing sessions. Postgrad Med J. 2015;91(1074):182-7. https://doi.org/10.1136/ postgradmedj-2014-132847.

21. Wolfe H, Zebuhr C, Topjian AA, Nishisaki A, Niles DE, Meaney PA, et al. Interdisciplinary ICU cardiac arrest debriefing improves survival outcomes*. Crit Care Med. 2014;42(7):1688-95.

22. Bandari J, Schumacher $\mathbf{K}$, Simon M, Cameron D, Goeschel CA, Holzmueller CG, et al. Surfacing safety hazards using standardized operating room briefings and debriefings at a large regional medical center. Jt Comm J Qual Patient Saf. 2012;38(4):154-60. https://doi.org/ $10.1016 / \mathrm{s} 1553-7250(12) 38020-3$.

Publisher's Note Springer Nature remains neutral with regard to jurisdictional claims in published maps and institutional affiliations. 